\title{
English Intonation Teaching in a Perspective of Communicative Functions
}

\author{
Dongxiao Peng \\ Huanghe Science and Technology College \\ Zhengzhou, Henan, China
}

\begin{abstract}
English is an intonation language while Chinese is a tone language. English intonation with some distinctive features from Chinese intonation has communicative functions that endows a speaker's utterance with various attached meanings. The complexity and subtlety of English intonation cause English teachers and learners considerable troubles. Therefore the ability to understand and use English intonation should be one of the focuses in phonetics teaching and an important criterion to measure one's language ability.
\end{abstract}

Keywords-English intonation; communicative function; phonetics teaching

\section{INTRODUCTION}

Intonation is an important element of spoken English. The melody of language is regarded as intonation of speech. Intonation refers to the total pattern of pitch change, for instance, the rising and falling of the voice when a person is speaking, within an utterance. Intonation makes speech meaningful. English intonation shows the relationship of words within and between sentences and tells something about the feeling of the speaker. In other words, different pitches may indicate different meanings for the same utterance. Different pitches help speakers express different feelings such as happiness, sadness, surprise, annoyance, anger, and so on. In listening to the meaning of an utterance, therefore, we listen to how speakers talk as well as what they say. How speakers talk and what they say together give us the full meaning of an English utterance, so intonation makes the meaning of utterance $\mathrm{c}$ more complete and clearer.

This paper mainly talks about English intonation expounded by British phonetic system. There are several variations in English phonetics, such as American English, Australian English, and so on. Phonetic system and intonation groups may vary, but these do not affect mutual understanding through language communication.

\section{ENGLISH INTONATION UNITS AND THEIR SEGMENTATION}

The phonology consists of segmental phonology and super segmental phonology. Super segmental phonology emphasizes the study of stress and intonation. In order to understand intonation better we need to know intonation units and how to segment it. An intonation unit usually corresponds to a sense group or a word group. An intonation unit may contain several syllables, some of them stressed and some unstressed. At the same time, each intonation group should correspond to the piece of information conveyed by the speaker. An intonation group usually indicates how the speaker organizes or perceives the information. In each intonation group, there is a strongest syllable which is usually a marker of the highest importance is briefly regarded as the nucleus. A nucleus refers to the syllable in an intonation unit which carries maximal prominence and has focus stress. On this syllable, there takes place a change of pitch, either an upward or downward movement, or a combination of the two. A complete intonation unit consists of four parts of pre-head, head, nucleus, tail. Among them, the nucleus is the most important syllable which carries the greatest information and is a marker of the highest importance. Under normal circumstances, the nuclear will fall on the last stressed syllable.

\section{A. Nucleus of a Intonation Unit}

A nucleus refers to the syllable in an intonation unit which carries maximal prominence and reflects the change of pitch. For example, this is a normal way of saying the following sentence:

We were in a great Hurry.

There are seven syllables in total and two stressed syllables in this sentence, among which the last stressed syllable is HUR. So we say that HUR has the focus stress, and is the tonic syllable and therefore the nucleus of the intonation unit. The nucleus is the essential part of the intonation unit. It is still present even if the unit consists of a single syllable, as is the case with many sentence words like help, what, why.

\section{B. Tail of an Intonation Unit}

Tail is any syllable or syllables that may follow the nucleus in an intonation unit. In the sentence "We were in a great Hurry", the nucleus of this sentence is on the tonic syllable "HUR". There is one unstressed syllable "RY" after of the nucleus. This syllable is called the "tail" of this intonation unit.

\section{Head of an Intonation Unit}

The part of an intonation unit that extends from the first stressed syllable up to the nucleus is the "head" of this 
intonation unit. In the sentence "We were in a great Hurry", the head of this intonation unit is "GREAT".

\section{Prehead of an Intonation Unit}

Any unstressed syllable or syllables that may precede the "head", or the "nucleus" if there is no head, are called the "pre-head". In the sentence "We were in a great Hurry", "we were in a" comprises the "pre-head" of this intonation unit.

The following is a structure analysis of an intonation unit for "We were in a GREAT HUR ry" "Fig. 1":

\begin{tabular}{|l|} 
We were in a GREAT HUR ry \\
$\mathrm{P} \quad \mathrm{H} \quad \mathrm{N}$ \\
$\mathrm{P}=$ Pre-head \\
$\mathrm{H}=$ Head \\
$\mathrm{N}=$ Nucleus \\
$\mathrm{T}=$ Tail
\end{tabular}

Fig. 1. A structure analysis of an intonation unit for "We were in a GREAT HUR ry”

Following are the possible structures of an intonation unit "Fig. 1":

P H N T: They sang beautifully.
P H T: They couldn't even speak properly.
P N T: We hope so.
H N T: Are you hungry?
P N: It was at night.
H N: Peter has arrived.
N T: Help me!
N : Please!

Fig. 2. The possible structures of an intonation unit

The above analysis is the basic composition of an intonation unit. Through this analysis, we know the key to the segmentation of intonation unit is to determine the position of the nucleus. The position of the nucleus influences the other elements in an intonation unit. The following principles help to determine nucleus:

- a nucleus is the last fully stressed syllable in an intonation unit;

- a nuclear has the biggest pitch change in the unit;

- a nuclear can be longer and louder than other stresses in the same tone unit;

- a nuclear carries a lot of weight in conveying the message;

- a nuclear can be on any word or phrase in an intonation unit.

According to these principles, we find Principle one "A nucleus is the last fully stressed syllable in an intonation unit." and principle five "A nuclear can be on any word or phrase in an intonation unit." are inevitably contrary. This is the focused content of this paper on the variations of suprasegmental phonemes. The location of the nucleus in an intonation unit is relatively fixed, namely the last stressed syllable, but also highly flexible, namely "A nucleus can be on any word or phrase in a unit" which reflects the flexibility of the language itself. These are mutual complementarities of general principles and particular circumstances. "A nucleus falls on final stressed syllables in an intonation unit" is the normal way saying a sentence and it doesn't need to mark by linguists while the phenomena that the nucleus falls on other location are classified as marked by linguists. The marked are the phenomena in which tone groups are inconsistent with complete sentences.

Different nucleus conveys different messages, for example:

They flew to New York.

They flew to New York.

They flew to New York.

They flew to New York.

They flew to New York. The nucleus is on the last stressed syllable of the intonation unit, which is normal way in which the sentence is spoken in English. The last information word is usually the last stressed word which has the nucleus.

They flew to New York. The nucleus is on the preposition, to, which is not usually stressed. The speaker wants to emphasize direction: They flew to New York, not from New York.

They flew to New York. The nucleus is on the verb: Flew. The speaker wants to emphasize how they travelled: they flew to New York instead of took by ship.

They flew to New York. The nucleus is on the personal pronoun: they, which is not stressed normally. The speaker wants to emphasize who do this: they, not you or we.

In short, nucleus placing is important as English speakers use nucleus to focus listener's attention and make meaning clear and contrast information.

\section{FUNCTIONS OF ENGLISH INTONATIONS}

Intonation functions are complex and remain to be further research. Phonetic experts will typically summarize English intonation functions as the following four aspects: the attitudinal function, the accentual function, the grammatical function and the discourse function of intonation.

\section{A. The Attitudinal Function of Intonation}

Intonation can express the speaker's attitude obviously. Through tone a speaker can express their feelings and attitudes such as happiness, gratitude, anger, or boredom, etc. Usually, intonation units with high heads sound more lively and interesting than those with low heads. Generally the falling intonation is said to be more often associated with completeness and definiteness. The rising intonation mainly reflects the speaker's questioning, uncertain and incomplete attitude. The falling-rising intonation expresses the feelings of hesitation, contrast, reservation or doubt. 


\section{B. The Accentual Function of Intonation}

The location of tonic syllable is of considerable linguistic importance. The most common position for this is on the last information word of the intonation unit. For contrastive purposes, however, any word may be the tonic syllable.

\section{The Grammatical Function of Intonation}

The same sentence said in different intonation may lead to semantic differences. Some sentences may be ambiguous when written, but this can be removed by the use of intonation. For instance:

You are $\downarrow$ angry with me. (The speaker gives a statement)

You are $\rtimes$ angry with me? (The speaker is not certain and questioning)

-We must go to work on $\downarrow$ weekends. (The speaker is making an order)

-We must go to work on $\nearrow$ weekends? (But, it's legal holiday. The speaker is asking for information)

A: You are a teacher, \ aren't you? (The speaker is comparatively certain that the information is correct and simply asking for conformation)

B: You are a teacher, $\nearrow$ aren't you? (The speaker is not certain and asking for information)

\section{The Discourse Function of Intonation}

In speech, people often use intonation to focus the listener's attention on aspects of the message that are most important. So the placement of nucleus or tonic stress depends on the "information content". The discourse function of intonation is determined according to information weight in a given context. Generally speaking, the more predictable a word's occurrence is in a given context, the lower its information content is. For example
A : what are they $\downarrow$ building?
B: They're building a $\downarrow$ school.

A : what $\downarrow$ kind of school?

B: I think it's a $\downarrow$ trade school.

In this conversation, the nucleus is on the greatest information word. In speech, therefore, people often use the falling tone to indicate new information and rising tone to indicate "shared" of "given" information.

\section{THE ENLIGHTENMENT ON ENGLISH PRONUNCIATION TEACHING}

English is an intonation language while Chinese is a tone language. The phenomenon of the negative transfer of mother tongue is universal, that Chinese students tend to speak all the words in a flat tone and spend similar time on each English syllable. They cannot use intonation to communicate appropriately. On the other hand, in practical pronunciation teaching, teachers lay more emphasis on the individual English sounds and attach less importance to intonation and longer unit of speech sounds. It's quite necessary to adjust teaching content and teaching strategy and increase the proportion of intonation teaching.

Firstly strengthening English intonation theoretical teaching is helpful for students' pronunciation acquisition. A contrastive analysis between English intonation and Chinese tone will help Chinese students avoid the negative transfer of mother tongue. Observing the similarities and differences between these two languages can help students understand the features of there two languages. If students can master the functions of English intonation and the semantic relationship of different intonations well, it is an effective method to solve students' practical problems.

Secondly, the teaching the individual sound and intonation should are not separated from each other. In daily teaching, quite a few students are often found to habitually use the falling tone. When speaking in other tones, their intonations seem to be stiff and unnatural. Therefore, the correct word pronunciation and the correct sentence intonation are equally important. Teachers can guide students how to use different tone in a given context to convey information, different feelings and attitudes.

Thirdly strengthening the practical training. The key to pronunciation and intonation learning is practice. Practical activities in language teaching are essential for intonation teaching. Students need to make use of this theoretical knowledge in authentic contexts and grasp the functions of different tones. The teacher can organize all kinds of language practice activities, such as speech, debate, interview, drama, etc., and guide students to consciously overcome the influence $s$ of negative transfer of mother tongue.

Lastly, the teaching staff should actively explore multimedia audio-visual teaching mode based on computer $\mathrm{s}$ in English classroom, to meet the needs of both teaching and learning, to enable teachers to constantly enrich and update teaching contents, but also provide students with a more flexible space to learn English pronunciation.

\section{CONCLUSION}

Above all, the flexibility of English intonation contains the rich language information and the tone change conveys differently subtle meaning. The misuse of intonation will directly influence the communication effect. The function of intonation is much more abundant and complex than the phenomena listed in the paper. In fact, this paper is just a part of the general rule .In terms of English phonetics teaching, teachers should adjust teaching importance and the teaching method.

\section{REFERENCES}

[1] Bradford, B. Intonation in Context, Cambridge university press, 1988

[2] Hancock, M. English pronunciation in Use .Cambridge university press, 2003 
[3] Wang Guizhen. English pronunciation \& Intonation for Communication. High Education press, 2002 